\title{
Production of Bright Greenish Yellow Fluorescence in Figs Infected by Aspergillus Species in California Orchards
}

\author{
Mark A. Doster and Themis J. Michailides, Department of Plant Pathology, University of California, Davis and \\ Kearney Agricultural Center, Parlier 93648
}

\begin{abstract}
Doster, M. A., and Michailides, T. J. 1998. Production of bright greenish yellow fluorescence in figs infected by Aspergillus species in California orchards. Plant Dis. 82:669-673.

The relationship of bright greenish yellow fluorescence (BGYF) of dried figs under longwave UV light to colonization by Aspergillus fungi was determined. BGYF in naturally infected figs was associated with decay by only four fungal species: the aflatoxin-producing species Aspergillus flavus (both L and S strains) and A. parasiticus, and the aflatoxin nonproducers A. tamarii and A. alliaceus. BGYF was more likely to be visible internally (after cutting open the fig) than externally. For all four species associated with BGYF, some infected figs did not show BGYF. The absence of fluorescence is probably not associated with the fungal strain or isolate involved, since isolating Aspergillus spp. from nonfluorescent figs followed by inoculating other figs with these isolates resulted in BGYF. Many of the nonfluorescent figs had small fungal colonies ( $<7 \mathrm{~mm}$ in diameter), even though some figs with large colonies were also nonfluorescent. The additional colonization of figs by other fungi did not affect the occurrence of BGYF in figs colonized by fungi in Aspergillus section Flavi. Figs infected with A. flavus or A. parasiticus and showing no BGYF were occasionally contaminated with aflatoxin, while other figs showing BGYF and infected with A. flavus or A. tamarii had no aflatoxins. Although not as promising as originally hoped, BGYF might be of use to remove aflatoxin-contaminated figs for certain specific situations in California.
\end{abstract}

Additional keywords: Aspergillus nomius, Ficus carica, kojic acid

California produces more than $99 \%$ of the dried figs (Ficus carica L.) grown in the United States, and more than twothirds of the figs consumed in the United States (1). Figs can be very susceptible to fungal decay in the internal cavity of the fruit because of a natural opening in the fig fruit, the ostiole (13). Unfortunately, the most popular dried fig cultivar in California, Calimyrna ( $45 \%$ of the hectarage; 1 ), has a very large ostiole and is highly susceptible to fungal decay $(20,24)$. The cultivar Conadria ( $25 \%$ of the hectarage) has a smaller ostiole but can still have a problem with fungal decay, whereas the cultivar Black Mission (20\% of the hectarage) has a very small ostiole and rarely has fungal decay $(20,24)$.

Although many different Aspergillus spp. decay figs in California (10), there is special concern for decay by the aflatoxin-

Corresponding authors: Mark A. Doster and Themis J. Michailides; E-mail: mark@uckac.edu, themis@uckac.edu

This research was supported by USDA Cooperative Research Agreement No. 58-5325-1-194 and by the California Fig Institute.

Accepted for publication 2 March 1998.

Publication no. D-1998-0406-01R

(C) 1998 The American Phytopathological Society producing A. flavus Link:Fr. and A. parasiticus Speare. Aflatoxins, which are potent toxins and carcinogens, are regulated by most governments (33). Even though $A$. flavus and $A$. parasiticus are probably present in every fig orchard in California, the occurrence of fig decay by these aflatoxinproducing fungi is quite rare. For example, between 1991 and 1994 the mean incidence of fig decay caused by A. flavus and by $A$. parasiticus in commercial orchards was 0.04 and $0.01 \%$, respectively (10). Nevertheless, the amount of aflatoxin present in individual dried figs decayed by $A$. flavus and $A$. parasiticus can be very high $(>10,000 \mathrm{ng}$ aflatoxins per $\mathrm{g}$ fruit; 10). Furthermore, the maximum tolerated level for aflatoxins in foodstuffs set by governments is usually very low, typically less than $25 \mathrm{ng} / \mathrm{g}$ (33).

In the early 1950s, a bright greenish yellow fluorescence (BGYF) in raw cotton was discovered to be associated with infections of $A$. flavus (4). This finding became more important after A. flavus was found to also produce aflatoxins. As expected, BGYF was associated with aflatoxin contamination of cotton seed (2). Extensive research followed, resulting in BGYF being associated with A. flavus infections in corn (28) and in other plants (19). Several uses for BGYF have been developed, including as a presumptive test for aflatoxins (29), in identifying susceptible cultivars in breeding programs (26), and in the removal of aflatoxin-contaminated crops (3).

BGYF was associated with aflatoxin contamination in dried figs from Turkey (30). The cultural practices and climate in California, however, are very distinct from those in the dried fig-growing region near Izmir in Turkey, so research results for Turkish figs may not apply to California figs. The general aim of the present study was to determine the feasibility of using BGYF to remove aflatoxin-contaminated figs in California. The specific objectives of our study were to determine (i) the incidence and location of BGYF, (ii) the fungi associated with BGYF, (iii) the relationship between the fluorescence of individual figs and aflatoxin contamination, and (iv) why some figs infected with aflatoxinproducing fungi are not BGYF.

\section{MATERIALS AND METHODS}

General methods. Figs were cut open and examined for the presence of BGYF by placing them under the transmitted light of two 15-W longwave UV lamps (365 $\mathrm{nm}$ ) in a viewing cabinet that operates as a light-tight darkroom (Chromato-Vue C$70 \mathrm{G}$ UV Viewing System, Ultra-Violet Products, Inc., San Gabriel, CA). In addition, all figs were evaluated for fungal decay by examining the interior and exterior of the fig with a dissecting microscope $(10 \times)$ for the presence of fungal sporulation (except figs from orchard A in 1994, which were only examined with the microscope if a fungal colony was visible to the naked eye or if the fig was BGYF). All Aspergillus fungi from the figs were isolated into culture and identified to species using a taxonomic key and species descriptions (16). In addition, two strains of A. flavus were distinguished according to the size and abundance of sclerotia produced (7). Isolates were stored on silica gel at $6^{\circ} \mathrm{C}$ for future use (32). All figs infected with $A$. flavus or A. parasiticus from all orchards in 1993 and the Conadria orchards in 1994, and 15 infected figs from orchard A in 1994 , were stored at $-19^{\circ} \mathrm{C}$ for aflatoxin analysis.

The aflatoxins in 36 figs were quantified individually by two methods. Most figs were analyzed by the first method, which consisted of extracting aflatoxins according to the Romer method, an Association of Official Analytical Chemists (AOAC) official method $(25,31)$, and quantifying the aflatoxins in the extracts by high-pres- 
sure liquid chromatography (HPLC) with a $\mathrm{C}_{18}$ reversed-phase column and fluorescence detector after derivation with trifluoroacetic acid (9). Some figs were analyzed for aflatoxins by the DFA of California in Fresno, California using a second method, which used immunoaffinity columns (Vicam, Inc., Watertown, MA) for cleanup and quantified aflatoxins HPLC with post-column derivation and fluorescence detection (AOAC Method No. 991.31; 21). For both methods, the detection limit was less than $1 \mathrm{ng} / \mathrm{g}$.

Collection of naturally infected figs from commercial orchards. Dried figs were collected from the ground during harvests in commercial orchards in Fresno, Madera, and Merced counties. In general, figs were collected during several harvests between mid-August and early October. The number of Calimyrna figs examined for fungal decay and BGYF was 2,000 from each of eight orchards in 1993; 40,082 and 12,600 from orchards A and B, respectively, in 1994; 34,586 from orchard $\mathrm{B}$ in 1995; and 23,197 and 500 from orchard B and a third orchard, respectively, in 1996. The number of Conadria figs evaluated was 3,000 for each of three orchards in 1994 and 1,000 for each of two orchards in 1996.

Factors associated with production of BGYF. To investigate which fungal strains can produce BGYF, developing figs on trees in a research orchard were inoculated with isolates in Aspergillus section Flavi. On 11 August 1995, all figs on two shoots (2 to 12 usable figs per shoot) for each of 13 isolates were inoculated by placing 0.02 $\mathrm{ml}$ of spore suspension $\left(10^{7}\right.$ spores $\left./ \mathrm{ml}\right)$ in the ostiole. Six of these isolates were previously isolated from naturally infected figs showing no BGYF, three isolates were from figs showing BGYF, and four isolates were from substrates other than figs. On 8 September, all figs were removed and examined for signs of fungal infection and for BGYF. Isolations were made from the collected figs to verify that the same fungus was present as inoculated. Similarly, on 19 August 1996, all figs on five shoots for each of six isolates (three isolates originally from figs showing BGYF and three from nonfluorescent figs) were inoculated with a $0.02-\mathrm{ml}$ spore suspension $\left(>10^{7}\right.$ spores $/ \mathrm{ml}$ ), and on 11 September all figs were removed and evaluated. Prior to and after inoculation, all shoots were covered with cotton organdy bags to keep out insects and to prevent figs from falling to the ground. In addition, on 21 August 1997, developing Calimyrna figs were collected from a commercial orchard, inoculated with silica gel crystals containing conidia of the same 13 isolates used in 1995 (24 figs per isolate), and incubated at $30^{\circ} \mathrm{C}$ for 5 days followed by drying in the sun.

The effects of other factors, such as size of fungal colony and presence of other fungi, on BGYF were determined. For the figs collected from orchard B in 1995 and 1996, the diameter of colonies for fungi in Aspergillus section Flavi was measured. Other fungi present in these figs were identified as belonging to Aspergillus section Nigri, Fusarium spp., or dematiaceous fungi based on colony characteristics as seen with a dissecting microscope $(10 \times)$. Colonies of Aspergillus section Nigri and dematiaceous fungi were periodically isolated into pure culture to verify identifications.

Data analysis. In general, statistical analysis of data was descriptive. Analysis of variance was used with least significant difference (LSD) for separation of means. For counts, Fisher's exact test was used (11). All analyses were done with SAS (release 6.11, SAS Institute Inc., Cary, NC).

\section{RESULTS}

General characteristics of BGYF in naturally infected figs. For California figs naturally infected with Aspergillus section Flavi, BGYF was more likely to be visible internally (after cutting open the fig) than externally (Table 1$)$. Only rarely $(<10 \%$ of the infected figs) was the fig exterior colonized by these fungi. Furthermore, between 7 and $59 \%$ of the infected figs (depending on the orchard, year, and fig type) showed no BGYF (Table 1).

Infected product and cull figs differed quantitatively in showing BGYF (Table 1). In both 1995 and 1996, product figs had fewer figs showing BGYF externally than the cull figs (statistically significant by Fisher's exact test, $P=0.05$ ). In addition, the overall incidence of BGYF in product figs was less than that in cull figs (statistically significant in 1995 but not in 1996; Fisher's exact test, $P=0.05$; Table 1).

Association of BGYF with decay by Aspergillus spp. in naturally infected figs. BGYF was found to be associated with decay by only four species in two Aspergillus sections but not with decay by

Table 2. Association of bright greenish yellow fluorescence (BGYF) with natural infections of Aspergillus spp. in figs from commercial orchards ${ }^{\mathrm{x}}$

\begin{tabular}{|c|c|c|c|c|c|}
\hline \multicolumn{2}{|c|}{ Aspergillus } & \multicolumn{2}{|c|}{ Calimyrna figs } & \multicolumn{2}{|c|}{ Conadria figs } \\
\hline Section & Species $^{y}$ & BGYF/Total ${ }^{z}$ & BGYF (\%) & BGYF/Total ${ }^{z}$ & BGYF (\%) \\
\hline \multirow[t]{4}{*}{ Flavi } & A. flavus strain $\mathrm{L}$ & $59 / 64$ & 92 & $3 / 7$ & 43 \\
\hline & A. flavus strain $\mathrm{S}$ & $12 / 13$ & 92 & $1 / 2$ & 50 \\
\hline & A. parasiticus & $18 / 21$ & 86 & $2 / 4$ & 50 \\
\hline & A. tamarii & $158 / 203$ & 78 & $6 / 18$ & 33 \\
\hline Circumdati & A. alliaceus & $3 / 4$ & 75 & $3 / 4$ & 75 \\
\hline
\end{tabular}

x The Calimyrna figs were from the 1993, 1995, and 1996 harvests, while the Conadria figs were from 1994 and 1996

y The following Aspergillus spp. were isolated from figs but were never associated with BGYF (in parentheses is the number of naturally infected figs examined): A. carbonarius (12), A. japonicus (18), A. niger (1,070), A. ochraceus (17), A. sydowii (50), A. terreus (61), A. wentii (11), and Eurotium spp. (103).

${ }^{\mathrm{z}}$ Number of figs.

Table 1. The incidence and location of bright greenish yellow fluorescence (BGYF) in Calimyrna figs naturally infected with Aspergillus section Flavi

\begin{tabular}{|c|c|c|c|c|c|c|c|}
\hline \multirow[b]{3}{*}{ Orchard } & \multirow[b]{3}{*}{ Year } & \multirow[b]{3}{*}{ Fig type $^{x}$} & \multirow[b]{3}{*}{ Number of infected figs examined } & \multicolumn{4}{|c|}{ Percentage of infected figs in each category } \\
\hline & & & & \multirow[b]{2}{*}{$\begin{array}{l}\text { Fungal colony } \\
\text { on exterior }^{\mathrm{y}}\end{array}$} & \multicolumn{3}{|c|}{ Fungal colony in interior } \\
\hline & & & & & $\begin{array}{c}\text { Internal } \\
\text { BGYF only }\end{array}$ & $\begin{array}{c}\text { Internal and } \\
\text { external BGYF }\end{array}$ & $\begin{array}{c}\text { No } \\
\text { BGYF }\end{array}$ \\
\hline A & 1994 & Product & 203 & 1 & 62 & 30 & 7 \\
\hline B & 1995 & Product & 47 & 2 & 56 & 19 & 23 \\
\hline B & 1995 & Culls & 140 & 4 & 20 & 64 & 13 \\
\hline B & 1996 & Product & 32 & 0 & 41 & 0 & 59 \\
\hline B & 1996 & Culls & 32 & 9 & 53 & 25 & 13 \\
\hline
\end{tabular}

${ }^{\mathrm{x}}$ Figs were sorted into two groups. Figs were considered culls if they had obvious external blemishes; otherwise, figs were considered product.

${ }^{\mathrm{y}}$ For all figs with external colonies, $82 \%$ showed external BGYF.

z "External BGYF" means BGYF visible under longwave UV lamps (365 nm) prior to cutting the fig open, while "internal BGYF" means BGYF was visible after cutting the fig in half and examining the interior of the fig. No figs with a colony of Aspergillus section Flavi in the fig interior showed only external BGYF. 
any other Aspergillus sp. (Table 2). All three species in Aspergillus section Flavi that were isolated from California figs ( $A$. flavus, $A$. parasiticus, and A. tamarii) were associated with BGYF. Furthermore, both the $\mathrm{L}$ and $\mathrm{S}$ strains of $A$. flavus produced BGYF. The only fungal species not in Aspergillus section Flavi that was associated with BGYF was A. alliaceus in Aspergillus section Circumdati. For all four Aspergillus spp. associated with BGYF, some infected figs did not show BGYF (Table 2). The numbers of figs showing BGYF were not significantly different for figs infected by A. tamarii, A. flavus, or A. parasiticus for orchard A in 1994 and orchard B in 1995 and 1996 (Fisher's exact test, $P=$ $0.05)$. In general, a lower percentage of infected Conadria figs showed BGYF than infected Calimyrna figs (Table 2).

Aflatoxin contamination was associated with BGYF in California figs, but the relationship was complicated (Table 3). Some figs infected with A. flavus or A. parasiticus but showing no BGYF were contaminated with aflatoxin (Table 3). Conversely, some figs showing BGYF and infected with A. flavus or A. tamarii were not contaminated with aflatoxins (Table 3 ).

Factors associated with production of BGYF. For all fungal isolates tested, al-

Table 3. Relationship between bright greenish yellow fluorescence (BGYF) and aflatoxin contamination in individual figs naturally infected with Aspergillus section Flavi ${ }^{\mathrm{y}}$

\begin{tabular}{|c|c|c|}
\hline Species & No BGYF & Visible BGYF ${ }^{\mathrm{z}}$ \\
\hline A. flavus & $1 / 7$ & $14 / 20$ \\
\hline A. parasiticus & $2 / 2$ & $3 / 3$ \\
\hline A. tamarii & $0 / 0$ & $0 / 4$ \\
\hline
\end{tabular}

y Figs were collected from various commercial orchards in 1993, 1994, and 1995.

${ }^{\mathrm{z}}$ Number of figs, aflatoxin detected/total. most all infected figs showed BGYF, even if the isolate was obtained from nonfluorescent figs (Table 4). In 1995, only 1 of 106 infected figs did not show BGYF, whereas, in 1996, at least one fig infected with each isolate tested did not show BGYF (Table 4). All three aflatoxin-producing species, including $A$. nomius, resulted in BGYF figs. All isolates shown in Table 4 were also tested in detached figs in the laboratory and resulted in BGYF figs.

Naturally infected figs with large colonies ( $>10 \mathrm{~mm}$ diameter) of fungi in Aspergillus section Flavi were more likely to show BGYF than figs infected with small colonies (<7 mm diameter) in both 1995 and 1996 (Table 5). Nevertheless, even some figs with large colonies were not BGYF. Figs with an intermediate-size colony (between 7 and $10 \mathrm{~mm}$ in diameter) had a substantially higher percentage showing BGYF than figs with smaller colonies in 1995 but about the same in 1996 (Table 5).

Table 5. The relationship of internal fungal colony size in Calimyrna figs naturally infected with Aspergillus section Flavi (collected from orchard B) and the incidence of bright greenish yellow fluorescence (BGYF)

\begin{tabular}{lcc}
\hline & \multicolumn{2}{c}{ Figs that showed BGYF (\%) } \\
\cline { 2 - 3 } Diameter $^{\mathbf{y}}$ & $\mathbf{1 9 9 5}$ & $\mathbf{1 9 9 6}$ \\
\hline$<7$ & $67.9 \mathrm{a}^{\mathrm{z}}$ & $52.4 \mathrm{a}$ \\
7 to 10 & $92.9 \mathrm{~b}$ & $53.4 \mathrm{a}$ \\
$>10$ & $95.0 \mathrm{~b}$ & $91.2 \mathrm{~b}$ \\
\hline
\end{tabular}

$\mathrm{y}$ The colony diameter $(\mathrm{mm})$ was calculated as the mean of two perpendicular diameters of the fungal colony inside the fig.

${ }^{\mathrm{z}}$ Statistical analysis was performed on arcsine transformed data. Numbers followed by the same letter are not significantly different $(P=$ 0.05 ) by pairwise comparisons using Fisher's least significant difference test. Values presented were back-transformed from the means for the arcsine-transformed data.
The additional presence of other fungi in the figs infected with fungi in Aspergillus section Flavi did not seem to affect the presence of BGYF. In 1995 in orchard B, $85.7 \%$ of 119 figs infected only with $A s$ pergillus section Flavi (that is, no other fungus present) showed BGYF, while $79.7 \%$ of 59 infected figs also colonized by other fungi showed BGYF (not statistically significantly different by Fisher's exact test, $P=0.05)$. In 1996 in orchard B, $60.0 \%$ of 35 figs infected only with Aspergillus section Flavi showed BGYF, while $65.4 \%$ of 26 infected figs also colonized by other fungi showed BGYF (not statistically significantly different by Fisher's exact test, $P=0.05$ ). The most common coinfecting fungi were Aspergillus section Nigri (60 and $62 \%$ of the figs infected by both Aspergillus section Flavi and other fungi in 1995 and 1996, respectively), dematiaceous fungi (26 and 24\%), and Fusarium spp. (5 and 3\%).

\section{DISCUSSION}

For California figs naturally infected with Aspergillus section Flavi, BGYF is usually not visible externally but only internally, especially for the product figs (Table 1). In contrast, the vast majority of infected Turkish figs showed external BGYF (30). This difference between California figs and Turkish figs might be due to the part of the fig colonized by the fungi. In California, infections by Aspergillus section Flavi occurred predominantly inside the fig ostiole and cavity (10; Table 1). In Turkey, aflatoxin contamination was associated with the part of the fig showing surface fluorescence (30) and with poorer grade figs consisting of damaged and crushed figs (5). Thus, infections might occur mainly externally in Turkish figs.

Four different Aspergillus spp. produced BGYF in naturally infected California figs

Table 4. Production of bright greenish yellow fluorescence (BGYF) in Calimyrna figs inoculated with various isolates in Aspergillus section Flavi in a research orchard ${ }^{\mathrm{w}}$

\begin{tabular}{|c|c|c|c|c|c|}
\hline \multirow[b]{2}{*}{ Isolate } & \multirow[b]{2}{*}{ Species } & \multicolumn{2}{|c|}{1995} & \multicolumn{2}{|c|}{1996} \\
\hline & & BGYF/Infected $^{\mathrm{x}}$ & BGYF (\%) & BGYF/Infected $^{\mathrm{x}}$ & BGYF (\%) \\
\hline \multicolumn{6}{|c|}{ Isolates from figs showing BGYF: } \\
\hline A796 & A. tamarii & $6 / 6$ & 100 & $20 / 21$ & 95 \\
\hline A798 & A. flavus strain $\mathrm{L}$ & $6 / 6$ & 100 & $28 / 29$ & 97 \\
\hline A800 & A. parasiticus & $8 / 8$ & 100 & $21 / 22$ & 96 \\
\hline \multicolumn{6}{|c|}{ Isolates from figs not showing BGYF: } \\
\hline A794 & A. flavus strain $\mathrm{L}$ & $12 / 12$ & 100 & $22 / 23$ & 96 \\
\hline A962 & A. parasiticus & $8 / 8$ & 100 & $25 / 27$ & 93 \\
\hline A963 & A. tamarii & $9 / 9$ & 100 & $21 / 23$ & 91 \\
\hline A967 & A. parasiticus & $11 / 11$ & 100 & $\mathrm{nd}^{\mathrm{y}}$ & nd \\
\hline A968 & A. flavus strain $\mathrm{S}$ & $7 / 7$ & 100 & nd & nd \\
\hline A971 & A. tamarii & $8 / 8$ & 100 & nd & nd \\
\hline \multicolumn{6}{|c|}{ Isolates not from figs: } \\
\hline A630 & A. flavus strain $\mathrm{S}$ & $11 / 11$ & 100 & nd & nd \\
\hline NRRL13137z & A. nomius & $4 / 5$ & 80 & nd & nd \\
\hline NRRL6552 & A. nomius & $4 / 4$ & 100 & nd & nd \\
\hline A813 & A. flavus strain $\mathrm{S}$ & $11 / 11$ & 100 & nd & nd \\
\hline
\end{tabular}

\footnotetext{
${ }^{\mathrm{w}}$ In addition to the results presented in the table, all of the isolates produced BGYF in Calimyrna figs that were detached and inoculated in the laboratory.

${ }^{x}$ Number of figs.

y Not determined.

${ }^{\mathrm{z}}$ Type culture.
} 
(Table 2). The association of BGYF with A. flavus has been previously reported for figs (30), corn (28), cotton (4), and other crops (19). Two morphologically and physiologically distinct strains of A. flavus, the $\mathrm{L}$ and the $\mathrm{S}$ strain, are found in cotton fields (7) and in California fig orchards (10). Distinguishing these two strains is important, because they differ in their aflatoxin production. The L strain is inconsistent and variable in aflatoxin production, with many isolates producing no aflatoxins, whereas the $\mathrm{S}$ strain is consistently associated with high aflatoxin production $(7,10)$. Both strains are associated with BGYF in cotton (7) and in figs (Table 2). In addition, A. parasiticus was also associated with BGYF in Turkish (30) and California figs (Table 2). A third species in Aspergillus section Flavi, A. nomius, also produces aflatoxins (17). A. nomius did produce BGYF in inoculated figs (Table 4), although this species has never been found to decay figs in commercial orchards.

This is the first report of BGYF for crops naturally infected with $A$. tamarii and $A$. alliaceus (Table 2). Even though $A$. tamarii and $A$. alliaceus do not produce aflatoxins, A. tamarii isolates from California fig orchards produce the mycotoxin cyclopiazonic acid and A. alliaceus produces the mycotoxin ochratoxin in figs (10). A possible reason why A. tamarii was not found in BGYF figs from Turkey could be that $A$. tamarii may be less common in Turkey than in California. A. tamarii decays approximately the same number of figs in California orchards as A. flavus (10). Although the levels of A. tamarii in Turkish fig orchards are unknown, in Turkish pistachio orchards A. tamarii does occur at very low levels and is much rarer than A. flavus $(8,15)$.

BGYF and aflatoxin contamination are not always associated with each other in California figs. Many figs showing BGYF have no aflatoxins (Table 3), because these figs are infected with a species such as $A$. tamarii (which does not produce aflatoxins) or with A. flavus (which has many isolates that do not produce aflatoxins; 10). In contrast, only a small percentage (10 out of 62 figs) of Turkish figs showing BGYF did not have any aflatoxins (30). This discrepancy may be attributed to the higher incidence of $A$. tamarii in California than in Turkey. Furthermore, not all aflatoxin-contaminated figs are BGYF. Some individual California figs showing no BGYF are contaminated with aflatoxins (Table 3), and removal of Turkish figs showing BGYF did not remove all of the aflatoxin (30). Likewise, small amounts of aflatoxins were present in some nonfluorescent cotton seed samples (3), and nonfluorescent corn kernels infected with A. flavus can be contaminated with aflatoxins (12).

BGYF in cotton results when A. flavus produces kojic acid, which is then converted to the fluorescent compound by peroxidase in the plant (19). Therefore, Aspergillus spp. known to produce kojic acid would be expected to produce BGYF. Kojic acid is produced by species in Aspergillus sections Flavi, Wentii, and Circumdati (14). A. flavus, A. parasiticus, and A. tamarii in Aspergillus section Flavi have been shown to produce kojic acid (23). As would be expected, all three species produced BGYF in naturally infected figs (Table 2) and in inoculated figs (Table 4). A. alliaceus in Aspergillus section Circumdati has been reported to produce kojic acid (6) and produced BGYF in California figs, although A. ochraceus, also in Aspergillus section Circumdati, did not (Table 2). Strangely, A. wentii is reported to produce kojic acid $(6,14)$ but did not produce BGYF in California figs (Table 2). In addition, BGYF is not produced in dead plant tissue infected with A. flavus (19). Although inoculation with A. flavus of figs while on the tree resulted in BGYF (Table 4), inoculation of autoclaved figs did not produce any BGYF even though there was abundant fungal growth (M. Doster and T. Michailides, unpublished results). Fungi can also provide the peroxidase needed to convert the kojic acid to the fluorescent compound (34). Nevertheless, in our study, the presence of other fungi in figs infected with Aspergillus section Flavi did not enhance the production of BGYF.

Some California figs naturally infected with Aspergillus section Flavi do not show BGYF (Tables 1 and 2). Fungi isolated from nonfluorescent figs did produce BGYF when inoculated in other figs and, for all six isolates tested in 1996, some infected figs did not show BGYF (Table 4). Thus, some factor other than the fungal strain is involved with these nonfluorescent infected figs. Exposure to sunlight decreases the intensity of $\operatorname{BGYF}(18,30)$, although that should have little effect on the internal BGYF so common in California figs infected with Aspergillus section Flavi. Although many of the nonfluorescent figs had small fungal colonies, some figs with large colonies still were not fluorescent (Table 5). Finally, the absence of plant peroxidases (19) and fungal peroxidases (34) may explain some of the nonfluorescent infected figs.

BGYF is used commercially in Turkey to remove aflatoxin-contaminated figs $(22,27)$. In California, however, BGYF will probably not be used for the removal of contaminated product figs or as a presumptive test for aflatoxin in figs because of the high percentage of contaminated figs only having internal fluorescence, especially among the product figs (Table 1). Nevertheless, BGYF might be useful for decreasing aflatoxin contamination during the manufacturing of fig paste (because figs are cut in quarters during processing) or other specific situations.

\section{ACKNOWLEDGMENTS}

We thank L. D. Boeckler, D. P. Morgan, and D. Felts for technical assistance; R. Klamm and S. Klamm for assistance in sampling; P. Cotty for providing A. nomius isolates; M. Hurley and the staff of the DFA of California for assistance in aflatoxin analyses; and the fig growers who cooperated in this research.

\section{LITERATURE CITED}

1. Anonymous. 1997. Statistical Review of the California Fig Industry. California Fig Institute, Fresno.

2. Ashworth, L. J., and McMeans, J. L. 1966. Association of Aspergillus flavus and aflatoxins with a greenish yellow fluorescence of cotton seed. Phytopathology 56:1104-1105.

3. Ashworth, L. J., McMeans, J. L., Pyle, J. L., Brown, C. M., Osgood, J. W., and Ponton, R. E. 1968. Aflatoxins in cotton seeds: Influence of weathering on toxin content of seeds and on a method for mechanically sorting seed lots. Phytopathology 58:102-107.

4. Bollenbacher, K., and Marsh, P. B. 1954. A preliminary note on a fluorescent-fiber condition in raw cotton. Plant Dis. Rep. 38:375379.

5. Boyacioglu, D., and Gonul, M. 1990. Survey of aflatoxin contamination of dried figs grown in Turkey in 1986. Food Addit. Contam. 7:235-237.

6. Ciegler, A., Burmeister, H. R., and Vesonder, R. F. 1983. Poisonous fungi: Mycotoxins and mycotoxicoses. Pages 413-469 in: Fungi Pathogenic for Humans and Animals. Part B Pathogenicity and Detection. D. H. Howard, ed., M. Dekker, New York.

7. Cotty, P. J. 1989. Virulence and cultural characteristics of two Aspergillus flavus strains pathogenic on cotton. Phytopathology 79:808-814.

8. Denizel, T., Jarvis, B., and Rolfe, E. J. 1976. A field survey of pistachio (Pistacia vera) nut production and storage in Turkey with particular reference to aflatoxin contamination. J. Sci. Food Agric. 27:1021-1026.

9. Doster, M. A., and Michailides, T. J. 1994. Aspergillus molds and aflatoxins in pistachio nuts in California. Phytopathology 84:583590.

10. Doster, M. A., Michailides, T. J., and Morgan, D. P. 1996. Aspergillus species and mycotoxins in figs from California orchards. Plant Dis. 80:484-489.

11. Everitt, B. S. 1977. The Analysis of Contingency Tables. John Wiley \& Sons, New York.

12. Fennell, D. I., Bothast, R. J., Lillehoj, E. B., and Peterson, R. E. 1973. Bright greenishyellow fluorescence and associated fungi in white corn naturally contaminated with aflatoxin. Cereal Chem. 50:404-414.

13. Ferguson, L., Michailides, T. J., and Shorey, H. H. 1990. The California fig industry. Hortic. Rev. 12:409-490.

14. Frisvad, J. C. 1989. The connection between the Penicillia and Aspergilli and mycotoxins with special emphasis on misidentified isolates. Arch. Environ. Contam. Toxicol. 18:452-467.

15. Heperkan, D., Aran, N., and Ayfer, M. 1994. Mycoflora and aflatoxin contamination in shelled pistachio nuts. J. Sci. Food Agric. 66:273-278.

16. Klich, M. A., and Pitt, J. I. 1988. A Laboratory Guide to Common Aspergillus Species and Their Teleomorphs. CSIRO Division of Food Processing, North Ryde, Australia.

17. Kurtzman, C. P., Horn, B. W., and Hesseltine, C. W. 1987. Aspergillus nomius, a new aflatoxin-producing species related to Aspergillus flavus and Aspergillus tamarii. Antonie van Leeuwenhoek 53:147-158.

18. Marsh, P. B., Simpson, M. E., Ferretti, R. J., 
Campbell, T. C., and Donoso, J. 1969. The relation of aflatoxins in cotton seeds at harvest to fluorescence in the fiber. J. Agric. Food Chem. 17:462-467.

19. Marsh, P. B., Simpson, M. E., Ferretti, R. J., Merola, G. V., Donoso, J., Craig, G. O., Trucksess, M. W., and Work, P. S. 1969. Mechanism of formation of a fluorescence in cotton fiber associated with aflatoxins in the seeds at harvest J. Agric. Food Chem. 17:468472.

20. Obenauf, G., Gerdts, M., Leavitt, G., and Crane, J. 1978. Commercial Dried Fig Production in California. Univ. Calif. Div. Agric. Sci. Leaflet 21051.

21. Official Methods of Analysis. 1995. 16th Ed., AOAC, Arlington, VA

22. Ozay, G., and Alperden, I. 1991. Aflatoxin and ochratoxin - a contamination of dried figs (Ficus carica L.) from the 1988 crop. Mycotoxin Res. 7:85-91.

23. Parrish, F. W., Wiley, B. J., Simmons, E. G., and Long, L. 1966. Production of aflatoxins and kojic acid by species of Aspergillus and
Penicillium. Appl. Microbiol. 14:139.

24. Phillips, E. H., Smith, E. H., and Smith, R. E. 1925. Fig Smut. Univ. Calif. Agric. Exp. Stn. Bull. 387.

25. Romer, T. R. 1975. Screening method for the detection of aflatoxins in mixed feeds and other agricultural commodities with subsequent confirmation and quantitative measurement of aflatoxins in positive samples. J. Assoc. Off. Anal. Chem. 58:500-506.

26. Scott, G. E. 1996. Association of bright greenish yellow fluorescence and aflatoxin in grain of maize inbreds. Maydica 41:43-48.

27. Sharman, M., Patey, A. L., Bloomfield, D. A., and Gilbert, J. 1991. Surveillance and control of aflatoxin contamination of dried figs and fig paste imported into the United Kingdom. Food Addit. Contam. 8:299-304.

28. Shotwell, O. L., Goulden, M. L., and Hesseltine, C. W. 1972. Aflatoxin contamination: Association with foreign material and characteristic fluorescence in damaged corn kernels. Cereal Chem. 49:458-465.

29. Shotwell, O. L., and Hesseltine, C. W. 1981.
Use of bright greenish yellow fluorescence as a presumptive test for aflatoxin in corn. Cereal Chem. 58:124-127.

30. Steiner, W. E., Rieker, R. H., and Battaglia, R. 1988. Aflatoxin contamination in dried figs: Distribution and association with fluorescence. J. Agric. Food Chem. 36:88-91.

31. Stoloff, L., and Scott, P. M. 1984. Natural poisons. Pages 477-500 in: Official Methods of Analysis of the Association of Official Analytical Chemists. 14th ed. S. Williams, ed., Association of Official Analytical Chemists, Arlington, VA.

32. Trollope, D. R. 1975. The preservation of bacteria and fungi on anhydrous silica gel: An assessment of survival over four years. J. Appl. Bacteriol. 38:115-120.

33. van Egmond, H. P., and Dekker, W. H. 1995. Worldwide regulations for mycotoxins in 1994. Nat. Toxins 3:332-336.

34. Wicklow, D. T., and Hesseltine, C. W. 1979. Fluorescence produced by Aspergillus flavus in association with other fungi in autoclaved corn kernels. Phytopathology 69:589-591. 